\title{
А.В. Шентякова
}

\section{ЭЛЕКТОРАЛЬНЫЕ ПРЕДПОЧТЕНИЯ ГОРОЖАН \\ И ЖИТЕЛЕЙ СЕЛЬСКОЙ МЕСТНОСТИ НАКАНУНЕ ВЫБОРОВ В ГОСУДАРСТВЕННУЮ ДУМУ VII СОЗЫВА (на примере Ханты-Мансийского автономного округа)}

\begin{abstract}
Статья посвящена изучению взаимосвязи между местом проживания избирателей и их политическими ориентациями и ценностями. В работе анализируются результаты эмпирического исследования, проведенного в июле-августе 2016 г. в Ханты-Мансийском автономном округе. Анализ данных серии фокус-групп позволил выявить устойчивые различия политических установок и предпочтений у жителей крупных городов и сельской местности. Были выделены наиболее значимые факторы, влияющие на мотивацию электорального поведения, и партийные предпочтения избирателей различных возрастных групп. Проанализированы образы «идеального кандидата» в сельской местности и городе. Сделаны выводы о сохраняющихся традиционных культурных расколах между городом и селом. Библиогр. 8 назв.

Ключевые слова: политические предпочтения, электоральное поведение, политические партии, образ идеального кандидата, выборы.
\end{abstract}

\section{A. V. Shentyakova \\ THE ELECTORAL PREFERENCES OF CITIZENS AND INHABITANTS OF RURAL AREA BEFORE THE ELECTIONS TO THE STATE DUMA OF CONVENING VII (on KhMAO example)}

The paper studies the relationship between the place of residence of voters and their political orientations and values. The paper analyzes the results of empirical research conducted in July-August 2016 in Khanty-Mansiysk Autonomous Okrug. Analysis of the data series of focus groups revealed differences stable political attitudes and preferences of residents of large cities and rural areas. They have been identified the most important factors affecting the motivation of electoral behavior and party preferences of voters of different age groups. Analyzed images of the "ideal candidate" in the countryside and the city. Conclusions about the remaining traditional cultural split between urban and rural areas. Refs 8.

Keywords: political preferences, voting behaviour, political parties, the image of the ideal candidate, election.

Выборы как один из институтов демократизации общества, с одной стороны, обеспечивают легитимность и легальность существующей власти, с другой - способствуют ее трансформации в соответствии с изменяющимися условиями и потребностями общества. Избирательная система - один из ключевых институтов демократии, обеспечивающий каналы связи общества со структурами государственной власти. Выборы, занимающие центральное место в избирательной системе, представляют собой главный инструмент соперничества и борьбы за власть между различными конкурирующими и противоборствующими социально-

Шентякова Анна Владимировна - кандидат политических наук, ассистент, Санкт-Петербургский государственный университет, Российская Федерация, 199034, Санкт-Петербург, Университетская наб., 7-9; anna_pedagog@mail.ru

Shentyakova Anna V. - PhD, Assistant Professor, St Petersburg State University, 7-9, Universitetskaya nab., St Petersburg, 199034, Russian Federation; anna_pedagog@mail.ru

(c) Санкт-Петербургский государственный университет, 2017 
политическими силами и интересами $[1$, с. 86]. Изменения избирательного законодательства, которые последовали после электорального цикла 2011-2012 гг., актуализировали соперничество между кандидатами в депутаты Государственной Думы в одномандатных округах. Основная борьба за голоса избирателей развернулась на уровне регионов, в которых проходили одновременно выборы в федеральный парламент и местные законодательные органы власти. Региональные различия РФ по экономическим, культурным, социальным, этническим и др. критериям существенны, поэтому представляется интересным и актуальным изучать электоральные процессы в региональном срезе с учетом отличительных особенностей и специфики каждого субъекта.

Результаты избирательного цикла 2016 г. в очередной раз продемонстрировали региональные различия в поведении и предпочтениях избирателей. Задача электоральной географии - сопряженное изучение политических предпочтений на разных территориальных уровнях, но для понимания процессов, происходящих в российском обществе, необходим каждый уровень в отдельности [2, с. 70]. Одновременно с региональными различиями, электоральные предпочтения населения отличаются в зависимости от типов населенных пунктов. «Степень урбанизации относится к числу важнейших факторов территориальной дифференциации электоральных предпочтений. Контраст между городскими и сельскими районами - одна из главных закономерностей географии выборов в России» [2, с. 70]. Для жителей избирательных округов с высокой долей урбанизации характерны более либеральные ценностные ориентации, готовность голосовать за новых политических лидеров, проведение курса реформ, чаще в качестве требований к кандидатам звучат способность быстро адаптироваться к изменениям и высокая мобильность. В то же время сельские жители, по опросам прошлых лет, демонстрировали приверженность консервативным убеждениям, ценностям порядка, справедливости, стабильности и постепенности.

Все акторы избирательного процесса разрабатывают предвыборные стратегии, ориентируясь на запросы и интересы своего основного объекта - электората. Исследовать проблему электорального поведения - значит установить, как люди принимают решение об участии в выборах, и рассмотреть те факторы, которые оказывают воздействие на электоральное поведение [3, с.79]. Поведение избирателей определяется их политическими предпочтениями. Многочисленные зарубежные и отечественные исследования показали, что политические предпочтения обусловлены принадлежностью людей к различным национальным, культурным, социальным и профессиональным группам и общностям. Поведение избирателей определяется их пересекающейся принадлежностью к различным социальным общностям не непосредственно, а через механизм социальной идентификации. Возникающая на основе перекрестного давления социальных общностей пересекающаяся конфигурация социальных идентификаций обусловливает характер политической идентификации людей, которая оказывает непосредственное воздействие на их голосование на выборах [4, с.5]. Отдельно необходимо выделить такой важный фактор, влияющий на поведение избирателей, как ценностные ориентации. «Ценностные ориентации являются самостоятельным фактором формирования и изменения политических предпочтений. Причем речь идет не о любых, а о базовых ориентациях избирателей, занимающих центральное место в системе 
мотивации их поведения» [4, с. 5]. Для предвыборной кампании ценностные ориентации населения того или иного округа играют определяющую роль. Как известно, ценности - это общепринятые убеждения относительно целей, к которым нужно стремиться (терминальные ценности), и средств, которые можно использовать для достижения этих целей (инструментальные ценности) [5, с. 4].

Исследователи, занимающиеся изучением электорального поведения, выделяют два основных подхода: поведенческий и институциональный. В рамках поведенческого подхода были разработаны три основные модели анализа электорального поведения:

1. «Социологическая» модель основана на утверждении, что голосование выражает стремление людей солидаризироваться с мнением своей социальной группы. Она ориентирует исследователей на выявление зависимости индивидуального и группового политического выбора от объективного экономического, социального и демографического статуса людей.

2. «Социально-психологическая» модель исходит из того, что в своем выборе люди руководствуются укоренившимися политическими предпочтениями. В рамках этой модели голосование на выборах рассматривается как продукт всего предыдущего политического опыта человека.

3. Модель «рационального выбора» рассматривает голосование как выражение реакции людей на конкретную сложившуюся историческую ситуацию [6].

В основу проведенного исследования была положена социологическая модель поведенческого подхода. Для изучения базовых ценностных установок, политических предпочтений и электоральных ожиданий чаще всего применяют качественные методы сбора и анализа данных. Фокусированные групповые интервью позволяют собрать информацию непосредственно у респондентов, не ограничивая их рамками опросных формализованных техник. Фокус-группа направлена на определение отношения участников к поставленной проблеме или причин восприятия того или иного объекта и в полной мере отражает концептуальную основу интерпретационного подхода. Участник фокус-группы, обладающий широким полем интерпретативных механизмов, сформированным опытом конфликтных столкновений разного рода, «прочитывает» предлагаемую модератором гипотетическую ситуацию и идентифицирует себя с субъектами ситуационного действия $[7$, c.30].

За месяц до выборов в Ханты-Мансийском автономном округе (XМАО) была проведена серия из 10 фокус-групп в различных населенных пунктах. Группы были гетерогенными по гендерному составу, но однородными по возрастному критерию. Шесть групп были организованы в городах и четыре группы - в крупных сельских поселениях. Численность каждой группы составляла от 8 до 14 человек. В одну из групп, проведенных в выбранных одномандатных округах, приглашались избиратели в возрасте от 25 до 45 лет включительно, в другую - избиратели в возрасте старше 50 лет. Сценарий всех групп состоял из трех блоков.

Первый блок сценария был посвящен нерешенным проблемам и отношению жителей к своему городу/поселку. Социальное самочувствие жителей находится на уровне ниже среднего. Однако четко выделяют различия в оценке между жителями села и горожанами. В городах ситуация представляется менее депрессивной, осо- 
бенно в плане проявления протестных настроений. Сельчане чаще всего отмечали низкий уровень жизни и заработной платы: «Устраиваются в городах. Потому что там плотность населения больше и есть развлечения разные, и магазинов целые кучи. А здесь же ничего нет»; отсутствие рабочих мест: «Молодежь в основном остается там, где учится»; недостаточный уровень финансовой поддержки социально незащищенных слоев населения и низкий уровень социальной ответственности власти в целом. Со слов респондентов, «здесь можно неплохо жить, но для этого нужно работать на нескольких работах» либо «нести предпринимательские риски». Наиболее позитивно ситуация воспринимается представителями более молодого поколения, которые чувствуют практически ничем не ограниченную свободу выбора для своего развития. Не обремененные семейными обязательствами, отвечающие сами за себя, они оценивают сложившуюся ситуация не так критично, как представители среднего возраста или пенсионеры, на которых лежит груз ответственности за семью или необходимость ежедневно решать вопрос о том, как прожить на ту пенсию, которую они получают от государства, заплатить за квартиру или купить лекарства. Участники всех групповых дискуссий многократно подчеркивали, что если ты потерял трудоспособность, постарел или вышел на пенсию, завел детей и т.д., то ты становишься социально уязвимым человеком, у которого резко сокращается количество возможностей для нормального существования. Именно такие характеристики жизни обусловили основные требования к кандидатам, которые в случае избрания должны будут отстаивать интересы своих избирателей на федеральном уровне.

Второй блок был посвящен характеристике «идеального кандидата». Анализ данных фокус-групп позволил выделить наиболее значимые качества, которыми должен обладать кандидат, чтобы за него проголосовали избиратели-горожане. Во-первых, участники групповых интервью отмечали, что депутат должен быть не моложе 38 лет, так как «более молодые люди еще не знают жизни», «еще ничего не видели», «не доказали, что способны чего-то добиваться». В то же время его возраст не должен превышать 60 лет, так как «нужно много сил и энергии для выполнения своих обещаний». Возраст кандидатов оказался одинаково значимым фактором для всех избирателей, но есть отличия. Если в городе участники отмечали готовность голосовать «за молодых людей как наиболее активных, современных, способных что-то поменять», то в сельских населенных пунктах, наоборот, предпочтение отдавалось более старшим по возрасту кандидатам. Аргументами выступали жизненный опыт, умение общаться с народом и наличие связей в политике, без которых нет возможности добиться поставленных целей. А все эти ресурсы появляются только с возрастом.

Уровень образования и профессия также являются важными признаками. Необходимо отметить, что участники фокус-групп более старшего возраста подчеркивали, что профессия кандидата должна быть не «новомодной», когда «непонятно, чем человек занимается», а рабочей. В качестве подходящих назывались чаще всего врач, учитель, военный, специалист нефтяной отрасли. Среди специальностей упоминались административные работники из органов исполнительной власти, но чаще всего в негативном интенциональном окрасе. При выборе кандидата участники дискуссии отмечали, что важна не только профессиональная сфера, но и опыт работы. «Молодые специалисты не знают специфики района/региона, 
имеют слабое представление о проблемах, которые необходимо решать»; «депутат должен на любом уровне владеть информацией как по России, так и в какой-то степени в сфере международных отношений»; «хорошо знать обстановку непосредственно на своем участке, где какие предприятия. Должен знать хорошо социальную политику, как живет население и в чем нуждается»; «он должен владеть всей ситуацией, не только на территории, которая под его юриспруденцией, но и о городской, и областной, и федеральной. Потому что исходя из этого он должен планировать свою работу».

Для сельских жителей более важными условиями оказались место рождения, длительность профессиональной деятельности в их родном регионе, семейный статус. Укорененность кандидата, длительность его работы и проживания в ХМАО были названы в числе первых, наиболее важных характеристик кандидата. «Главное, чтобы человек родился и вырос в наших северных условиях, знал и понимал, что для нас важно. Ведь мы не Москва, и у нас многое отличается» (мужчина, 54 года). Для сельских избирателей положительным фактором при выборе из молодых кандидатов оказался родительский капитал. Участники фокус-групп неоднократно указывали, что «важно, когда знаешь, кто его родители, как он учился в школе, с кем водил дружбу в детстве и юношестве, служил ли в армии». В то же время в городе тот же самый фактор избиратели отмечали скорее как негативный. Участники групп говорили, что «семейственность в политике - это плохо. У нас не монархия, и власть не должна передаваться от отца к сыну» (женщина, 51 год).

Важными показателями для избирателей, проживающих в городе, являются профессиональная принадлежность будущих депутатов и уровень осведомленности о городских и региональных проблемах. «Он должен знать, чем будет заниматься после избрания», «если он не понимает, какие проблемы нужно решать, то какая польза будет нашему региону, округу?» (женщина, 47 лет).

В одномандатных округах, где происходила острая борьба за избирателей, партийные предпочтения накладывали отпечаток на электоральное поведение. Партийные предпочтения избирателей за месяц до выборов были четко выражены, поэтому полученные «Единой Россией» результаты не вызвали удивления. Подсчет голосов в ХМАО, согласно данным Центральной избирательной комиссии, показал, что 54 \% избирателей проголосовали за «Единую Россию», по 13 \% набрали партии КПРФ и ЛДПР, «Справедливая Россия» набрала $6 \%$ [8].

Третий блок был сконцентрирован на оценках политических партий и их предвыборной деятельности. Среди активных партий большинство называли «Единую Россию» и ЛДПР. В меньшей степени - «Справедливую Россию» и КПРФ. Другие партии никак себя не проявили, не ассоциировались с конкретными фигурами на региональном или федеральном уровне. Исключение составляет фигура губернатора, которая четко ассоциировалась с партией власти.

Анализ оценок избирателей показывает достаточно сильные позиции «Единой России» по округам. Среди кандидатов, по мнению участников дискуссий, присутствуют яркие, известные персоны, которые вызывали положительные отклики избирателей. Среди партий, ведущих избирательную кампанию, все участники назвали в первую очередь «Единую Россию» и отметили ее активность. Систематизация и анализ ответов респондентов позволили выделить следующие мотивы готовности проголосовать за «Единую Россию» и ее кандидатов: 
1. Наличие больших возможностей и ресурсов для эффективной работы. «Выбирать нужно сильного, того, кто победит».

2. Поддержка большинства населения, готовность поддержать партию, за которую голосует большинство.

3. Нежелание каких-либо кардинальных перемен, боязнь возможных изменений, которых «было уже достаточно», «как бы не было хуже».

4. Авторитет высшего руководства страны: лидера партии - Владимира Путина, продолжающего пользоваться уважением и доверием населения.

Самым сильным компонентом имиджа партии является ее полное отождествление с властью. Работа органов власти и ответственность за их работу возлагается на партию. Здесь срабатывают традиционные установки в сознании старшей возрастной группы избирателей, которые способствуют отождествлению «Единой России» с КПСС. Одновременно этот фактор работает против партии власти, так как большинство участников фокус-групп продемонстрировали сформировавшееся представление о том, что при своей силе и имеющихся возможностях партия ничего не делает, не проявляет себя в конкретных и значимых для развития города/ поселка и региона в целом направлениях. К основным демотиваторам можно отнести следующие:

1. В сознании молодого поколения присутствуют устойчивые негативные ассоциации, которые отталкивают от «Единой России». Отсутствие сильных позитивных изменений, понижение уровня жизни населения, большое количество нерешаемых актуальных проблем (ЖКХ, развал промышленности, реформа образования и здравоохранения, борьба с коррупцией и т. п.) обусловливают ожидание новых персон в поле публичной политики и продолжения реформ.

2. Избиратели-горожане часто обвиняли представителей федерального уровня в отсутствии контроля за своими ставленниками на местах, невыполнении обещаний, которые давались на предыдущих выборах. Во всех дискуссиях участники отмечали отсутствие активности местных депутатов, их нежелание помогать. Многократно говорилось об отсутствии реакции при обращении граждан к главам районов или администраций. Все участники групп говорили об отсутствии отчета по работе местных администраций и о том, что депутаты не устраивают встреч с избирателями для обсуждения и совместного решения местных проблем. Многие респонденты считают, что необходимы новые люди, главное условие - готовность работать, «что-то менять к лучшему, решать не только свои личные проблемы, но и городские/поселковые».

Уже на фокус-группах была заметна тенденция снижения популярности партии «Справедливая Россия», которая на предыдущих выборах пользовалась доверием. Причина этого лежит как в идейном компоненте: избирателей привлекали идея партии, заложенная в названии, а также основные пункты программы и заметность партии в СМИ. Именно со «Справедливой Россией» часть населения связывала ожидания более эффективных изменений развития страны, избирателей привлекала направленность партии в сторону решения социальных проблем. Но те, кто на прошлых выборах голосовал за «Справедливую Россию», выражают 
разочарование, отмечают, что депутаты этой партии не уделяют достаточно внимания простым жителям, не проводят встреч с ними в периоды до выборов.

К мотиваторам голосования за «Справедливую Россию» можно отнести следующие:

1. Популярность федеральных и региональных лидеров. Миронов воспринимается как сильный, популярный лидер, способный выступить с критикой «Единой России». Дмитриева оценивается как успешный и компетентный профессионал, который отстаивает социальные программы.

2. Необходимость присутсвия в органах власти других партий, которые могут договориться с «Единой Россией». Для всех участников старшей возрастной группы характерна уверенность, что более слабым политическим партиям необходимо уметь добиваться консенсуса с парламентскими лидерами, так как они больше зависят от своего электората и поэтому лучше представляют ожидания избирателей.

В голосовании за КПРФ присутствовали три основных мотива:

1. Идейный: привычка голосовать за коммунистов, особенно это демонстрируют респонденты старшего возраста.

2. Протестный: как вариант протестного голосования, вместо «против всех» - этот вариант чаще демонстрировали молодые мужчины, проживающие в городе.

3. Голосование за оппозиционную партию, которая предлагает альтернативный курс развития страны, - как мотив чаще всего встречался у женской половины респондентов.

Популярность ЛДПР связана в первую очередь с популярностью ее лидера Владимира Жириновского. Избирателям нравятся его выступления по телевидению, где он показывает себя грамотным и образованным политиком, открыто высказывает свое мнение, не боится говорить правду. В глазах лояльной к нему части участников фокус-групп сформировался его образ как борца с коррупцией и несправедливостью. Более нейтральная часть отдающих свои предпочтения ЛДПР (особенно это заметно среди молодых участников в сельской местности) объяснила свой выбор желанием «хоть как-то расшевелить это болото». Здесь преобладают эмоциональные мотивы.

На фокус-группах были представлены как те, кто совсем не определился с выбором, так и те, кто колеблется между двумя партиями. В ситуации, когда им необходимо сделать выбор в пользу одной из партий, они ориентируются на свой прежний опыт (голосуют по привычке) или же, напротив, для разнообразия решают изменить прежние политические предпочтения. Значимым фактором для неопределившихся является наличие среди кандидатов тех, кто зарекомендовал себя как успешные, состоявшиеся. Подавляющее большинство при выборе между двумя партиями чаще всего колебалось между «Единой Россией» и ЛДПР. Для этой группы избирателей основными факторами, определяющими электоральное поведение, являются фамилии известных кандидатов, конкретные лидеры, а не лозунги и программы. 
Полученные результаты позволяют сделать следующие выводы:

1. Ценностный раскол между городом и селом сохраняет свою актуальность для выбранного региона. Особенно это заметно при конструировании образов «идеального кандидата».

2. Присутствуют когортные различия в партийных предпочтениях. Для более молодых участников избирательного процесса важно, чтобы кандидат имел доступ к властным, экономическим и медийным ресурсам. Представители старшей возрастной группы больше внимания уделяют биографиям, опыту кандидатов. Участники фокус групп старше 50 лет подчеркивают, что голосование за партию - это осознанный выбор в пользу стабильности и предсказуемости.

3. Объединяющим компонентом для всех участников исследования можно назвать готовность изменить свои партийные предпочтения, если появится кандидат, который будет «больше делать, чем говорить» и который выстроит свою работу по принципу «решил поставленную задачу - отчитался». Нехватка диалога между гражданами и властью, отсутствие открытых публичных переговорных площадок и бесед между избранными депутатами и электоратом сформировались в осознанную потребность общества, которой на данном этапе российского политического процесса неоправданно пренебрегают.

\section{Литература}

1. Примова Э. Н. Реформа избирательной системы // Власть. 2009. № 9. С. 86-89.

2. Колосов В.А., Бородулина Н. А. Электоральные предпочтения избирателей крупных городов России: типы и устойчивость // Политические исследования. 2004. № 4. С. 70-79.

3. Филиппова E. В. Модели электорального поведения в предвыборных кампаниях Забайкальского края // Вестн. Челябинского гос. ун-та. 2010. № 31. С. 79-85.

4. Артемов Г.П. Характер изменения политических установок и ценностных ориентаций петербургских избирателей // Политический анализ: Доклады Центра эмпирических политических исследований СПбГУ. Вып. 6 / под ред. Г. П. Артемова. СПб.: Изд-во С.-Петерб. ун-та, 2005. С. 4-27.

5. Артемов Г. П. Ценностные ориентации, политическая культура и партийные предпочтения // Политический анализ: Доклады Центра эмпирических политических исследований СПбГУ. Вып. 4 / под ред. Г.П. Артемова. СПб.: Изд-во С.-Петерб. ун-та, 2003. С. 4-21.

6. Данилов А.В. Основные подходы к изучению электорального поведения // Политический анализ: Доклады Центра эмпирических политических исследований СПбГУ. Вып. 6 / под ред. Г.П. Артемова. СПб.: Изд-во С.-Петерб. ун-та, 2005. С. 76-86.

7. Щукин Д.А. Ментально-смысловое поле как фактор политического конфликта // Политический анализ: Доклады Центра эмпирических политических исследований СПбГУ. Вып. 8 / под ред. Г.П. Артемова. СПб.: Изд-во С.-Петерб. ун-та, 2007. С. 28-40.

8. Официальный сайт Центральной избирательной комиссии URL: http://www.vybory. izbirkom.ru/region/region/izbirkom?action=show\&root=1\&tvd $=100100067795854 \& v r n=1001000677958$ 49\&region=0\&global=1\&sub_region=0\&prver $=0 \&$ pronetvd=0\&vibid $=100100067795854 \&$ type $=233$ (дата обращения: 10.12.2016).

Для цитирования: Шентякова А. В. Электоральные предпочтения горожан и жителей сельской местности накануне выборов в Государственную Думу VII созыва (на примере Ханты-Мансийского автономного округа) // Вестник СПбГУ. Политология. Международные отношения. 2017. Т. 10. Вып. 1. C. 30-38. DOI: 10.21638/11701/spbu06.2017.104. 


\section{References}

Russian)

1. Primova E. N. Reforma izbiratel'noi sistemy [Electoral reform]. Vlast', 2009, no. 9, pp. 86-89. (In

2. Kolosov V.A., Borodulina N.A. Elektoral'nye predpochteniia izbiratelei krupnykh gorodov Rossii: tipy i ustoichivost' [Electoral Preferences in large cities of Russia: Types and Stability]. Politicheskie issledovaniia, 2004, no. 4, pp.70-79. (In Russian)

3. Filippova E. V. Modeli elektoral'nogo povedeniia v predvybornykh kompaniiakh Zabaikal'skogo kraia [The models of electoral behavior in the election campaign of the Trans-Baikal Territory]. Vestnik Cheliabinskogo gosudarstvennogo universiteta, 2010, no.31, pp.79-85. (In Russian)

4. Artemov G.P. Kharakter izmeneniia politicheskikh ustanovok i tsennostnykh orientatsii peterburgskikh izbiratelei [The nature of the change of political systems and values of St. Petersburg voters]. Politicheskii analiz: Doklady Tsentra empiricheskikh politicheskikh issledovanii SPbGU [Political analysis: Reports of the Center for Political SPbGU empirical research], vol. 6. Ed. by G. P. Artemov. St. Petersburg, St. Petersburg University Press, 2005, pp.4-27. (In Russian)

5. Artemov G.P. Tsennostnye orientatsii, politicheskaia kul'tura i partiinye predpochteniia [Value orientations, political culture and party preferences]. Politicheskii analiz: Doklady Tsentra empiricheskikh politicheskikh issledovanii SPbGU [Political analysis: Reports of the Center for Political SPbSU empirical research], vol. 4. Ed. by G. P. Artemov. St. Petersburg, St. Petersburg University Press, 2003, pp.4-21. (In Russian)

6. Danilov A.V. Osnovnye podkhody k izucheniiu elektoral'nogo povedeniia [The main approaches to the study of electoral behavior]. Politicheskii analiz: Doklady Tsentra empiricheskikh politicheskikh issledovanii SPbGU [Political analysis: Reports of the Center for Political SPbSU empirical research], vol. 6. Ed. by G. P. Artemov. St. Petersburg, St. Petersburg University Press, 2005, pp. 76-86. (In Russian)

7. Shchukin D. A. Mental'no-smyslovoe pole kak faktor politicheskogo konflikta [Mentally-semantic field as a factor of political conflict]. Politicheskii analiz: Doklady Tsentra empiricheskikh politicheskikh issledovanii SPbGU [Political analysis: Reports of the Center for Political SPbSU empirical research], vol. 6. Ed. by G. P. Artemov. St. Petersburg, St. Petersburg University Press, 2007, pp. 28-40. (In Russian)

8. Ofitsial'nyi sait Tsentral'noi Izbiratel'noi komissii [Official site of the Central Election Commission]. Available at: http://www.vybory.izbirkom.ru/region/region/izbirkom?action=show\&root $=1 \&$ tvd $=1001000$ $67795854 \& v r n=100100067795849 \&$ region $=0 \&$ global $=1 \&$ sub_region $=0 \&$ prver $=0 \&$ pronetvd $=0 \& v i b i d=10$ 0100067795854\&type=233 (accessed: 12/10/2016). (In Russian)

For citation: Shentyakova A. V. The electoral preferences of citizens and inhabitants of rural area before the elections to the State Duma of convening VII (on Khanty-Mansiysk Autonomous Okrug example). Vestnik SPbSU. Political science. International relations, 2017, vol. 10, issue 1, pp. 30-38. DOI: 10.21638/11701/ spbu06.2017.104.

Статья поступила в редакцию 5 ноября 2016 г. Статья рекомендована в печать 15 декабря 2016 г. 